Discussion Paper No. 820

\title{
MARKET SIZE AND \\ VERTICAL STRUCTURE \\ IN THE RAILWAY INDUSTRY
}

\author{
Noriaki Matsushima \\ Fumitoshi Mizutani
}

October 2011

The Institute of Social and Economic Research

Osaka University

6-1 Mihogaoka, Ibaraki, Osaka 567-0047, Japan 


\title{
Market Size and Vertical Structure in the Railway Industry*
}

\author{
Noriaki Matsushima ${ }^{\dagger}$ \\ Institute of Social and Economic Research, Osaka University \\ Fumitoshi Mizutani \\ Graduate School of Business Administration, Kobe University
}

October 7, 2011

\begin{abstract}
We provide a theoretical framework to discuss the relation between market size and vertical structure in the railway industry. The framework is based on a simple downstream monopoly model with two input suppliers, labor forces and the rail infrastructure firm. The operation of the downstream firm (i.e., the train operating firm) generates costs on the rail infrastructure firm. We show that the downstream firm with a larger market size is more likely to integrate with the rail infrastructure firm. This is consistent with the phenomenon in the railway industry.
\end{abstract}

JEL classification: L22, L13, R32

Key words: vertical integration, railway industry, market size, vertical coordination

${ }^{*}$ The authors gratefully acknowledge financial support from Grant-in-Aid for Encouragement of Young Scientists and for Basic Research from the Japanese Ministry of Education, Science and Culture. Any errors are the responsibility of the authors.

${ }^{\dagger}$ Corresponding author: Noriaki Matsushima, Institute of Social and Economic Research, Osaka University, Mihogaoka 6-1, Ibaraki, Osaka 567-0047, Japan. Phone: +81-6-6879-8571. E-mail: nmatsush@iser.osaka-u.ac.jp 


\section{Introduction}

Vertically integrated and separated firms coexist in many industries, a typical case being the rail industry. An important issue in the rail industry is whether to pursue a vertical separation policy, whereby a rail company is divided into two organizations, one responsible for rail operation and the other for rail infrastructure. There have been several variations in the vertical separation policy, including functional accounting separation (e.g. France in late 90s), organizational separation of rail operations and infrastructure (e.g. the UK, Netherlands), or organizational separation involving a holding company (e.g. Germany). While vertical separation has been carried out in some countries, massive horizontal separation of former state railways has been adopted in others (e.g. the UK and Japan). One important aim of organizational reforms in the rail industry is to create a competitive environment, with a vertical separation policy viewed as one option for stimulating competition.

There are quite clear policy differences between Europe and Japan. While vertical separation is a common policy in the European Union, vertical integration is still the structure of choice in the Japanese rail industry, notwithstanding the increasing incidence of vertical separation in local areas in Japan, such as in the cases of Aomori Railway and Sanriku Railway. While there are many examples of vertically separated railways in Europe, theoretical studies describing behavior resulting from this policy are few. We therefore provide an analytic framework to investigate this problem.

This paper investigates what factors determine the organization structure of railway companies. We construct a simple model including three players: a train operating company (firm $T$ ), a rail infrastructure company (firm $R$ ), and a labor union (group $L$ ). Firm $R$ and group $L$ respectively supply an essential input (e.g., the usage of rails) and labor force to firm $T$. Using those factors, firm $T$ supplies some units of the travel service to consumers who enjoy the travel service. By comparing their profits in the two situations of vertical integration and vertical separation, firms $R$ and $T$ determine whether or not they should be integrated vertically. We take into account the following factor: the operation by firm $T$ generates costs on firm $R$. 
Those costs include track maintenance, electrical systems maintenance, and the depreciation of infrastructure. Firm $R$ must pay a daily effort to reduce those track-related costs. This factor is important in ordinal track maintenance activities in the railway industry.

We show that firms $R$ and $T$ decide to integrate vertically if and only if the market size is large or the parameter related to the effort cost is small. The intuition behind the result is as follows. The quantity supplied by firm $T$ depends on the input prices set by group $L$ and firm $R$. Because the inputs supplied by group $L$ and firm $R$ are perfect complements, the sum of the input prices affects the quantity supplied by firm $T$. A higher input price set by an input supplier reduces the quantity supplied by firm $T$. Anticipating the shrink in quantity, another input supplier sets a lower input price. That is, the strategic interaction between the two suppliers is strategic substitution. Vertical separation is a credible commitment to set a higher input price of firm $R$. The rent-shifting from group $L$ to firm $R$ is beneficial from the viewpoint of firms $R$ and $T$. This effect depends on the market size. An increase in the market size enhances the quantity supplied by firm $T$. The increase in the quantity enlarges the importance of the reduction in per unit costs caused by the operation of firm $T$. That is, the vertical coordination between firms $R$ and $T$ becomes more important. To enhance the benefit from the effort for per unit cost reductions, firm $R$ lowers its input price to increase the quantity supplied by firm $T$. This implies that the rent-shifting effect of vertical separation becomes weak as the market size increases. The negative effect of coordination failure caused by vertical separation dominates the positive effect of the rent-shifting if the market size is large. Therefore, firms $R$ and $T$ vertically integrate if the market size is large. The result captures the conjecture suggested by Williamson (1985, p. 94): A larger firm will also be more likely to integrate if economies of scale in the "upstream" process result in lower costs for the large firm's own-production compared to a small firm.

The key feature of this model is that more than one input is required for the final product of the downstream monopolist. ${ }^{1}$ This feature is consistent with the examples mentioned above.

\footnotetext{
${ }^{1}$ This setting is related to models with complementary suppliers (Economides and Salop (1992), Nalebuff (2000), Baldwin and Woodard (2007), Casadesus-Masanell et al. (2007), and Maruyama and Minamikawa (2009)). Those papers discuss how mergers among complementary suppliers appear and/or how those mergers
} 
The model can be also applied to other industries. For instance, in the aircraft industry two major firms, Airbus and Boeing, rely heavily on firm-specific inputs (e.g., engines, wings, horizontal stabilizers) produced by independent manufacturers, and then sell their aircraft to airline companies, which are final customers (Beelaerts van Blokland et al. (2008)).

Several researchers have investigated how the structure of vertical organizations is determined in competitive environments (Bonanno and Vickers (1988), Gal-Or (1999), Choi and Yi (2000), Chen (2001, 2005), Lin (2006), Arya et al. (2008), Matsushima (2009)). Although these papers consider downstream competition to derive results for vertical separation, we show that vertical separation is profitable even with only one downstream firm. Two exceptions are Laussel (2008) and Matsushima and Mizuno (2009) who explicitly incorporate complementary inputs in attempts to examine why vertical integration does not occur. Besides several differences in the setup, the present paper differs from Laussel (2008) and Matsushima and Mizuno (2009) as our focus is primarily on the relation among vertical separation, market size, and the difficulty to reduce operation costs. The last factor is not incorporated into the models in Laussel (2008) and Matsushima and Mizuno (2009).

In a broad sense, since Coase's seminal work (1937), researchers have discussed the problem of vertical integration/separation with a transaction-cost-based approach. The related papers mainly deal with well-known hold-up problems that illustrate the underinvestment hypothesis (e.g., Grout (1984) and Tirole (1986)). Coase (1937) suggested that transaction costs might be avoided or reduced via other organizational structures, and Klein et al. (1978) and Williamson (1979) suggested vertical integration as an organizational response. The focus of this approach has been on comparing costs internal to a transaction, between organizing the transaction within a firm or through the market. ${ }^{2}$ Complementary to the transaction-cost based approach,

change equilibrium outcomes. Such complementary suppliers provide their products directly to consumers. This setting is quite different from ours. Note that the meaning of the term 'vertical integration' in these papers is different from that in our paper. Although a merger among complementary suppliers is called 'vertical integration' in these papers, in our model the term indicates a merger between an upstream and a downstream firm.

${ }^{2}$ Using the property rights approach to address the question of whether vertical integration can escape the hold-up problem, Grossman and Hart (1986) and Hart and Moore (1990) considered how a particular ownership 
this paper incorporating multiple inputs into the standard models with vertical relations.

The remainder of the paper is organized as follows: Section 2 explains the basic model and shows the main result. Section 3 extends the basic model. Section 4 provides concluding remarks.

\section{Model}

We explain the market structure in this paper.

There are three players related to train service provision to consumers. Firm $T$ (Train operating company) supplies some units of the train operation service to consumers. Firm $R$ (Rail infrastructure company) supplies an essential input (call it product $r$ ), in this case track related to infrastructure, to firm $T$. Group $L$ (Labor union) supplies labor (call it product $l$ ) to firm $T$. Consumers enjoy the train travel service. Inverse demand for the service is given as follows:

$$
p=\alpha-\beta q,
$$

where $p$ is the price, $q$ is the quantity supplied by firm $T$, and $\alpha$ and $\beta$ are positive constants. ${ }^{3}$

Firm $T$ needs one unit of product $l$ and one unit of product $r$ to produce one unit of train travel service. Firm $R$ and group $L$ individually offer per unit wholesale price $w_{r}$ and per unit wage of labor $w_{l}$ to firm $T$. The following figure depicts the market structure in this model.

\section{[Figure 1 here]}

Firm $T$ generates a cost for firm $R$. The cost is positively correlated to the quantity supplied by firm $T, q$. We assume that the cost is $C q$ where $C$ is a positive constant.

structure affects the parties' exposure to hold-ups. Che and Sákovics (2008) provided an excellent brief survey of the hold-up problem. The topic of vertical foreclosure is also related to the problem of vertical integration. The vertical foreclosure issue primarily concerns the relation between vertical integration and the competitiveness of downstream firms (e.g., Ordover et al. (1990) and Hart and Tirole (1990)). See also O'Brien and Shaffer (1992), McAfee and Schwartz (1994), Gaudet and Long (1996), Ma (1997), Riordan (1998), and Choi and Yi (2000). Rey and Tirole (2007) provide an excellent survey of the literature.

${ }^{3}$ In Section 3.1, we use a more generalized demand function. 
Let $\mathrm{u}$ briefly mention the cost structure in the railway industry. The role of a train operating company (firm $T$ ) is to provide service by running trains. Although the train operating company holds rolling stock and employees such as engineers and conductors, this company borrows rail tracks from a rail infrastructure company (firm $R$ ), to which it pays infrastructure charges. The rail infrastructure company holds rail infrastructure, maintaining tracks and electrical systems. Therefore, while the main costs of the train operating company are for labor, energy, administration, rolling stock, and infrastructure rental, the main costs of the rail infrastructure company are for track maintenance, electrical systems maintenance, and the depreciation of infrastructure. We believe that this accurately summarizes the cost structure of this industry.

Firm $R$ has an ability to reduce $C$ through its effort. The constant $C$ changes from $c$ to $c-e$ if firm $R$ pays its effort $e$ and incurs the effort cost $\gamma e^{2}$ where $c$ and $\gamma$ are positive constants.

Assumption 1 To secure that the equilibrium price $p$ is positive, we assume that $\beta \gamma \geq 1 / 3$.

Given the quantity supplied by firm $T$ is $q$, the consumer surplus is given as follows:

$$
C S \equiv \int_{0}^{q}(\alpha-\beta m) d m-(\alpha-\beta q) q=\frac{\beta q^{2}}{2} .
$$

The social surplus is the sum of the consumer surplus and the total profits in this market.

We investigate the incentive of firms $R$ and $T$ to integrate vertically. To do so, we consider two vertical structures: (1) Firms $R$ and $T$ are vertically separated; (2) Firms $R$ and $T$ are vertically integrated.

Vertical separation When firms $R$ and $T$ are vertically separated, the objective functions of the three players are given as follows:

$$
\pi_{L}=w_{l} q, \quad \pi_{T}=\left(p-w_{l}-w_{r}\right) q, \quad \pi_{R}=w_{r} q-(c-e) q-\gamma e^{2} .
$$

In standard oligopoly models with labor unions, each downstream firm negotiates with its labor union, which maximizes the product of its wage level and number of employees (for examples, see Horn and Wolinsky (1988a,1988b), Davidson (1988), Dowrick (1989), Mumford 
and Dowrick (1994), Naylor (2002), Lommerud et al. (2003), and Lommerud et al. (2009)). The model used here is the standard one concerning the objective function of labor union.

In this case, the game runs as follows:

1. Group $L$ and firm $R$ offer per unit wage level $\left(w_{l}\right)$ and per unit wholesale price (i.e., infrastructure charge) $\left(w_{r}\right)$ to firm $T$.

2. Given the wage level and the wholesale price, firm $R$ sets its effort level $e$ and firm $T$ sets the amount of service $q$ simultaneously.

Note that the timing of the game implies that firm $R$ 's effort does not have a nature of investment (credible commitment). If it has a nature of investment, the timing of the effort choice should be earlier than that of wage setting. Firm $R$ 's cost generated by firm $T$ is related to the operation of firm $T$. Firm $R$ has to pay its daily effort to reduce this cost. To capture the property of the cost-reducing efforts, we have assumed that the effort level $e$ is determined after the wage and the wholesale price are determined. We discuss how the timing structure affects the decision of vertical integration/separation in Section 3.2.

Vertical integration When firms $R$ and $T$ are vertically integrated (call them firm $I$ ), the objective functions of the two players are given as:

$$
\pi_{L}=w_{l} q, \quad \pi_{I}=\left(p-w_{l}\right) q-(c-e) q-\gamma e^{2},
$$

where $I$ indicates the integrated firm. $\pi_{I}$ is the sum of $\pi_{T}$ and $\pi_{R}$ in the case of vertical separation. The game runs as follows:

1. Group $L$ offers per unit wage level $\left(w_{l}\right)$ to $I$.

2. Given the wage level, $I$ sets its effort level $e$ and the amount of service $q$ simultaneously.

\section{$2.1 \quad$ Vertical separation}

We solve the game by backward induction. 
In the second stage, the profits of firms $T$ and $R$ are given as:

$$
\begin{aligned}
& \pi_{T}=\left(\alpha-\beta q-w_{l}-w_{r}\right) q, \\
& \pi_{R}=w_{r} q-(c-e) q-\gamma e^{2} .
\end{aligned}
$$

The first-order conditions of the firms lead to the quantity supplied by firm $T$ and the effort level of firm $R$ given the wage level and the wholesale price:

$$
\left\{\begin{array} { l } 
{ \frac { \partial \pi _ { T } } { \partial q } = \alpha - 2 \beta q - w _ { l } - w _ { r } = 0 , } \\
{ \frac { \partial \pi _ { R } } { \partial e } = q - 2 \gamma e = 0 , }
\end{array} \rightarrow \left\{\begin{array}{l}
q\left(w_{l}, w_{r}\right)=\frac{\alpha-w_{l}-w_{r}}{2 \beta} \\
e\left(w_{l}, w_{r}\right)=\frac{\alpha-w_{l}-w_{r}}{4 \beta \gamma}
\end{array}\right.\right.
$$

In the first stage, anticipating the outcome in the second stage, group $L$ and firm $R$ maximize their objectives:

$$
\begin{aligned}
\pi_{L} & =w_{l} q\left(w_{l}, w_{r}\right)=\frac{w_{l}\left(\alpha-w_{l}-w_{r}\right)}{2 \beta}, \\
\pi_{R} & =w_{r} q\left(w_{l}, w_{r}\right)-\left(c-e\left(w_{l}, w_{r}\right)\right) q\left(w_{l}, w_{r}\right)-\gamma\left(e\left(w_{l}, w_{r}\right)\right)^{2} \\
& =\frac{\left(\alpha-w_{l}-w_{r}\right)\left(\alpha-w_{l}+(8 \beta \gamma-1) w_{r}-8 \beta \gamma c\right)}{16 \beta^{2} \gamma} .
\end{aligned}
$$

Their reaction functions are given by the following functions and summarized as Figure 2 .

$$
w_{l}\left(w_{r}\right)=\frac{\alpha-w_{r}}{2}, \quad w_{r}\left(w_{l}\right)=\frac{(4 \beta \gamma-1) \alpha+4 \beta \gamma c-(4 \beta \gamma-1) w_{l}}{8 \beta \gamma-1} .
$$

[Figure 2 here]

When the market size increases (i.e., a decrease in $\beta$ ), the reaction function of $R$ moves downward (see Figure 2). To understand the reason, we can rewrite the profit of firm $R$ as follows:

$$
\begin{aligned}
\pi_{R} & =\left(w_{r}-c\right) q\left(w_{l}, w_{r}\right)+\left\{e\left(w_{l}, w_{r}\right) q\left(w_{l}, w_{r}\right)-\gamma\left(e\left(w_{l}, w_{r}\right)\right)^{2}\right\} \\
& =\frac{8 \beta\left(w_{r}-c\right)\left(\alpha-w_{l}-w_{r}\right)}{16 \beta^{2} \gamma}+\frac{\left(\alpha-w_{l}-w_{r}\right)^{2}}{16 \beta^{2} \gamma} .
\end{aligned}
$$

The first term is the direct net profit through its input. The second term is the 'gain' from the reduction of the negative externalities caused by firm $T$. This equation shows that an increase in the market size (i.e., a decrease in $\beta$ ) enhances the relative importance of the gain from the cost 
reduction (the second term). The second term is positively correlated to the quantity supplied by firm $T$. Note that, the marginal gain from the cost reduction is $\partial \pi_{R} / \partial e=q\left(w_{l}, w_{r}\right)-2 \gamma e$. Because $\partial q\left(w_{l}, w_{r}\right) / \partial w_{r}<0$, the positive correlation between the second term and $q\left(w_{l}, w_{r}\right)$ implies that an increase in the wholesale price set by firm $R, w_{r}$, monotonically decreases the second term. The second term is more important for the profitability of firm $R$ as the market size increases. Therefore, the wholesale price of firm $R$ monotonically decreases in the market size (i.e., a decrease in $\beta$ ).

Solving the simultaneous equations (the reaction functions), we have

$$
w_{l}^{*}=\frac{4 \beta \gamma(\alpha-c)}{12 \beta \gamma-1}, \quad w_{r}^{*}=\frac{(4 \beta \gamma-1) \alpha+8 \beta \gamma c}{12 \beta \gamma-1}, e^{*}=\frac{\alpha-c}{12 \beta \gamma-1}, q^{*}=\frac{2 \gamma(\alpha-c)}{12 \beta \gamma-1} .
$$

The equilibrium profits, the consumer surplus, and the social surplus are given as follows:

$$
\begin{aligned}
& \pi_{L}^{*}=\frac{8 \beta \gamma^{2}(\alpha-c)^{2}}{(12 \beta \gamma-1)^{2}}, \pi_{R}^{*}=\frac{(8 \beta \gamma-1) \gamma(\alpha-c)^{2}}{(12 \beta \gamma-1)^{2}}, \pi_{T}^{*}=\frac{4 \beta \gamma^{2}(\alpha-c)^{2}}{(12 \beta \gamma-1)^{2}}, \\
& C S^{*}=\frac{2 \beta \gamma^{2}(\alpha-c)^{2}}{(12 \beta \gamma-1)^{2}}, S W^{*}=\frac{(22 \beta \gamma-1) \gamma(\alpha-c)^{2}}{(12 \beta \gamma-1)^{2}}
\end{aligned}
$$

As a result, the sum of profits $\pi_{R}$ and $\pi_{T}$ is as follows:

$$
\pi_{R}^{*}+\pi_{T}^{*}=\frac{(\alpha-c)^{2} \gamma}{12 \beta \gamma-1}
$$

\subsection{Vertical integration}

We solve the game by backward induction.

In the second stage, the profit of firm $I$ and its first-order conditions are expressed as follows:

$$
\begin{aligned}
\pi_{I} & =\left(\alpha-\beta q-w_{l}-(c-e)\right) q-\gamma e^{2}, \\
\frac{\partial \pi_{I}}{\partial q} & =\alpha-2 \beta q-w_{l}-(c-e)=0, \\
\frac{\partial \pi_{I}}{\partial e} & =q-2 \gamma e=0 .
\end{aligned}
$$

The first-order conditions lead to

$$
q\left(w_{l}\right)=\frac{2 \gamma\left(\alpha-c-w_{l}\right)}{4 \beta \gamma-1}, \quad e\left(w_{l}\right)=\frac{\alpha-c-w_{l}}{4 \beta \gamma-1} .
$$


In the first stage, anticipating the outcome in the second stage, group $L$ maximizes its objective:

$$
\pi_{L}=w_{l} q\left(w_{l}\right)=\frac{2 w_{l} \gamma\left(\alpha-c-w_{l}\right)}{4 \beta \gamma-1} .
$$

The maximization problems lead to

$$
w_{l}^{* *}=\frac{\alpha-c}{2}, e^{* *}=\frac{\alpha-c}{2(4 \beta \gamma-1)}, q^{* *}=\frac{\gamma(\alpha-c)}{4 \beta \gamma-1} .
$$

The equilibrium profits, the consumer surplus, and the social surplus are given as

$$
\pi_{L}^{* *}=\frac{\gamma(\alpha-c)^{2}}{2(4 \beta \gamma-1)}, \pi_{I}^{* *}=\frac{\gamma(\alpha-c)^{2}}{4(4 \beta \gamma-1)}, C S^{* *}=\frac{\beta \gamma^{2}(\alpha-c)^{2}}{2(4 \beta \gamma-1)^{2}}, S W^{* *}=\frac{(14 \beta \gamma-3) \gamma(\alpha-c)^{2}}{4(4 \beta \gamma-1)^{2}} .
$$

\subsection{Comparison}

We first compare the several values of cases of vertical separation and vertical integration, which are derived in the previous subsections. Simple calculus leads to the following relations:

$$
w_{l}^{*}<w_{l}^{* *}, e^{*}<e^{* *}, q^{*}<q^{* *}, \pi_{L}^{*}<\pi_{L}^{* *}, S W^{*}<S W^{* *}
$$

Vertical separation causes the standard double marginalization problem. As a result, this reduces the quantity supplied by firm $T$ (i.e., the consumer surplus) and the social surplus. Therefore, vertical integration is preferable from the viewpoint of both consumer and social welfare. However, it does not occur for a larger parameter range as the following equation shows. When we compare the profit differences between vertical separation and vertical integration:

$$
\pi_{I}^{* *}-\left(\pi_{R}^{*}+\pi_{T}^{*}\right)=\frac{\gamma(\alpha-c)^{2}}{4(4 \beta \gamma-1)}-\frac{\gamma(\alpha-c)^{2}}{12 \beta \gamma-1}=\frac{(3-4 \beta \gamma) \gamma(\alpha-c)^{2}}{4(4 \beta \gamma-1)(12 \beta \gamma-1)} .
$$

This result is summarized as the following proposition:

Proposition 1 Under Assumption 1, vertical integration is preferable for firms $T$ and $R$ if and only if $\beta \gamma<3 / 4$.

Vertical separation induces group $L$ to lower its wage. The quantity supplied by firm $T$ is $q\left(w_{l}, w_{r}\right)$ which is decreasing in $w_{l}$ and $w_{r}$. Firm $R$ sets its wholesale price at a positive level $\left(w_{r}>0\right)$, although $w_{r}=0$ when firm $R$ is integrated by firm $T$. Because of the higher value 
of $w_{r}$ in the case of vertical separation, the monopoly power of group $L$ for firm $T$ is weaker than that in the case of vertical integration. This means that a portion of the monopoly profit of group $L$ is transferred to firm $R$ through 'competition' between the complementary input suppliers (Cournot (1838) and Sonnenschein (1968)). The rent-shifting from group $L$ to firm $R$ is beneficial from the viewpoint of firms $R$ and $T$. However, this effect depends on the market size. As explained earlier, as the market size becomes larger (i.e., $\beta$ becomes smaller), the wholesale price of firm $R, w_{R}$, becomes lower. This lower wholesale price allows group $L$ to set a higher wage, $w_{L}$. This means that the rent-shifting effect is weak if the market size is large. Therefore, the negative effect of coordination failure caused by vertical separation dominates the positive effect of the rent-shifting if the market size is large (i.e., $\beta$ is small).

\section{Extensions}

We extend the basic model to two directions. First, we generalize the demand function. Second, we change the timing structure of the basic models. We consider models in which firm $R$ engages in cost-reducing activities in the first stage, although in the previous section, it carries out those activities in the final stage.

\subsection{General function}

First, we discuss the level of robustness in the outcome derived in the previous subsections.

We assume that the inverse demand function is given as $P(Q / s)$ where $Q$ is the quantity supplied and $s$ represents the market size. The profits of firms $T$ and $R$ are given as follows:

$$
\pi_{T}=\left(P(Q / s)-w_{R}-w_{L}\right) Q, \quad \pi_{R}=w_{R} Q-(c-e) Q-I(e) .
$$

The first-order conditions are given as

$$
\begin{aligned}
& \frac{\partial \pi_{T}}{\partial Q}=P(Q / s)-w_{R}-w_{L}+P^{\prime}(Q / s) Q / s=0, \\
& \frac{\partial \pi_{R}}{\partial e}=Q-I^{\prime}(e)=0 .
\end{aligned}
$$

We arrange $\partial \pi_{T} / \partial Q$ as follows:

$$
\frac{\partial \pi_{T}}{\partial Q}=P(\tilde{Q})-w_{R}-w_{L}+P^{\prime}(\tilde{Q}) \tilde{Q}=0
$$


where $\tilde{Q} \equiv Q / s$. The value of $\tilde{Q}$ is derived by the above equation. This does not depend on the value of $s$ but depend only on the sum of $w_{R}$ and $w_{L}$. We can write the optimal quantity supplied by firm $T$ as follows:

$$
Q=s \tilde{Q}\left(w_{L}, w_{R}\right)
$$

Using the equation $\partial \pi_{T} / \partial Q=0$, we show how an increase of $w_{j}$ changes $Q\left(w_{L}, w_{R}\right)(j=L, R)$. Given the values of $s$ and $w_{i}$, the simple comparative statics of $\partial \pi_{T} / \partial Q=0$ with respect to $Q$ and $w_{j}(i=L, R$ and $i \neq j)$ leads to

$$
\frac{d Q\left(w_{L}, w_{R}\right)}{d w_{j}}=\frac{1}{S O C_{T}}<0,
$$

where $S O C_{T}$ represents the second-order condition of $\pi_{T}$.

The objectives of group $L$ and firm $R$ are given as

$$
\begin{aligned}
& \pi_{L}=s w_{L} \tilde{Q}\left(w_{L}, w_{R}\right), \\
& \pi_{R}=s w_{R} \tilde{Q}\left(w_{L}, w_{R}\right)-\left(c-e\left(s \tilde{Q}\left(w_{L}, w_{R}\right)\right)\right) s \tilde{Q}\left(w_{L}, w_{R}\right)-I\left(e\left(s \tilde{Q}\left(w_{L}, w_{R}\right)\right)\right) .
\end{aligned}
$$

The first-order conditions are given as

$$
\begin{aligned}
& \frac{\partial \pi_{L}}{\partial w_{L}}=s\left[\tilde{Q}\left(w_{L}, w_{R}\right)+w_{L} \frac{\partial \tilde{Q}\left(w_{L}, w_{R}\right)}{\partial w_{L}}\right]=0, \\
& \frac{\partial \pi_{R}}{\partial w_{R}}=s\left[\tilde{Q}\left(w_{L}, w_{R}\right)+\left(w_{R}-c+e\left(s \tilde{Q}\left(w_{L}, w_{R}\right)\right)\right) \frac{\partial \tilde{Q}\left(w_{L}, w_{R}\right)}{\partial w_{R}}\right]=0 .
\end{aligned}
$$

First, we find that $w_{L}\left(w_{R}\right)$ derived by the equation $\partial \pi_{L} / \partial w_{L}=0$ does not depend on the value of $s$. Second, we show that the value of $\partial \pi_{R} / \partial w_{R}$ between the brackets monotonically decreases in $s$. Differentiating it with respect to $s$, we obtain:

$$
\frac{\partial}{\partial s}\left(\frac{\partial \pi_{R}}{\partial w_{R}} \cdot \frac{1}{s}\right)=e^{\prime}\left(s \tilde{Q}\left(w_{L}, w_{R}\right)\right) \tilde{Q}\left(w_{L}, w_{R}\right) \frac{\partial \tilde{Q}\left(w_{L}, w_{R}\right)}{\partial w_{R}}<0 .
$$

This is because $\left.e^{\prime}\left(s \tilde{Q}\left(w_{L}, w_{R}\right)\right)\right)$ is an increasing function (see $\partial \pi_{R} / \partial e$ ) and $\partial \tilde{Q}\left(w_{L}, w_{R}\right) / \partial w_{R}$ is negative. The two properties are consistent with Figure 2.

\subsection{Does the timing of cost-reducing investments matter?}

We consider the models in which firm $R$ engages in cost-reducing activities in the first stage although it does in those activities in the final production stage in the previous section. Except 
the timing structures, the structures of the games are the same with those in the previous section. We explain the timing of the games.

Assumption 2 To secure that the equilibrium price $p$ is positive, we assume that $\beta \gamma \geq 1 / 12$.

In the case of vertical separation, the game runs as follows:

1. Firm $R$ sets its effort level $e$.

2. Observing the effort level, group $L$ and firm $R$ offer per unit wage level $\left(w_{l}\right)$ and per unit wholesale price $\left(w_{r}\right)$ to firm $T$.

3. Given the effort level, the wage level, and the wholesale price, firm $T$ sets the amount of service $q$.

Note that the timing of the game implies that firm $R$ 's effort has a nature of investment (credible commitment).

In the case of vertical integration, the game runs as follows:

1. Firm $I$ sets its effort level $e$.

2. Observing the effort level, group $L$ offers per unit wage level $\left(w_{l}\right)$ to firm $I$.

3. Given the effort and the wage levels, firm $I$ sets the amount of service $q$.

The calculus of the two cases lead to the following proposition (the calculus is summarized in the Appendix):

Proposition 2 Under Assumption 2, vertical separation is preferable for firms $T$ and $R$ for any $\beta \gamma$.

Under vertical separation, firm $R$ has full bargaining power over firm $T$. This means that firm $R$ internalizes its effort to reduce its marginal cost. ${ }^{4}$ Vertical integration does not greatly influence coordination problems between firms $R$ and $T$. Reducing the rent shifting from firm

\footnotetext{
${ }^{4}$ Note that firm $R$ cannot fully internalize its effort. This is because group $L$ also has full bargaining power over firm $T$. Group $L$ deprives of some rents generated by firm $R$ through its wage setting.
} 
$T$ to group $L$ is more important from the viewpoint of the firms. Therefore, vertical separation is always preferable.

This result is quite different from that in the previous section. In this section, the effort cost of firm $R$ is sunk before the wage and the wholesale price are determined. In the previous section, however, cost is incurred when firm $T$ sets its quantity supplied after the procurement conditions are determined. This implies that a coordination problem exists between firms $R$ and $T$. The discussion in this section clarifies that, in the vertical structure discussed here, the key factor of vertical integration is not the sunk-investment but the problem of coordination.

\section{Concluding remarks}

Vertically integrated and separated firms coexist in many industries, including railway. We have provided an analytic framework to investigate this problem. We show that the downstream firm which has the larger market size is more likely to integrate with the rail infrastructure firm. This is consistent with the phenomenon in the Japanese railway industry. The result captures the conjecture suggested by Williamson (1985, p. 94): A larger firm will also be more likely to integrate if economies of scale in the "upstream" process result in lower costs for the large firm's own-production compared to a small firm. Because many empirical studies infer that the hypothesis of transaction cost economics holds (Lafontaine and Slade (2007)), we believe that our prediction can be applied to many economic environments.

As Proposition 1 states, if market size increases, vertical integration is preferable, as shown in current empirical findings of Mizutani and Uranishi (2011) regarding the rail industry. By applying the total cost function to 30 railway organizations from 23 OECD countries for the 14 years between 1994 and 2007, Mizutani and Uranishi (2011) evaluate whether or not vertical separation caused a reduction in costs. The authors show that vertical separation effects with lower train density tend to reduce the total cost of a railway organization but as train density increases, vertical separation causes total costs to increase. This result means that vertical integration is preferable in the case of high train density while vertical separation is preferable in the opposite case. In their empirical analysis, train density is used but the measure (i.e. 
train density) is highly related to market size. The definition of train density is measured by how many trains run in a given railway network. If the market size is larger, then more train services are required in the market. Therefore, if rail organizations have a large market, it means that the rail organizations have larger train density. Thus, current empirical results support our theoretical implication.

As mentioned above, while vertical separation is a common policy in the European Union, vertical integration is still the structure of choice in the Japanese rail industry. Among vertical separation options, there are many variations. Within the largely vertically separated European rail industry, opinions have been voiced against the separation policy. Keeping in mind these various circumstances, we will provide theoretical background that may prove helpful in evaluating vertical separation policy in the rail industry.

In conclusion, our theoretical results show that policy related to vertical separation depends on market size, with vertical integration appropriate in rail organizations with a large market and vertical separation preferable in organizations with a small market. Based on our theoretical results, the European Commission's policy, which is that vertical separation policy should be applied everywhere, is not correct.

There are several ways to extend the monopoly model discussed here. Considering an oligopoly model is a natural extension of the current model. For instance, we can consider a situation in which two rail operation companies use the rails owned by two infrastructure firms. In Japan, some vertically integrated railway companies use their own rails cooperatively by operating their own trains from a terminal station owned by one of the companies to another terminal station owned by the other company. We think that an extended model can capture the essence of the Japanese and the EU railway industries and should be considered for future research. 


\section{Appendix}

We solve the two cases discussed in Section 3.2.

Vertical separation We solve the game by backward induction.

In the third stage, the profit of firm $T$ is given as:

$$
\pi_{T}=\left(\alpha-\beta q-w_{l}-w_{r}\right) q
$$

The first-order condition of the firm leads to the quantity supplied by firm $T$ given the effort and the wage levels and the wholesale price:

$$
\frac{\partial \pi_{T}}{\partial q}=\alpha-2 \beta q-w_{l}-w_{r}=0 \quad \rightarrow \quad q\left(w_{l}, w_{r}\right)=\frac{\alpha-w_{l}-w_{r}}{2 \beta} .
$$

In the second stage, anticipating the outcome in the third stage, group $L$ and firm $R$ maximize their objectives:

$$
\begin{aligned}
& \pi_{L}=w_{l} q\left(w_{l}, w_{r}\right)=\frac{w_{l}\left(\alpha-w_{l}-w_{r}\right)}{2 \beta}, \\
& \pi_{R}=\left(w_{r}-(c-e)\right) q\left(w_{l}, w_{r}\right)-\gamma e^{2}=\frac{\left(w_{r}-(c-e)\right)\left(\alpha-w_{l}-w_{r}\right)}{2 \beta}-\gamma e^{2} .
\end{aligned}
$$

Their reaction functions are given by the following functions.

$$
w_{l}\left(w_{r}\right)=\frac{\alpha-w_{r}}{2}, \quad w_{r}\left(w_{l}\right)=\frac{\alpha+c-e-w_{l}}{2} .
$$

Solving the simultaneous equations (the reaction functions), we have

$$
w_{l}(e)=\frac{\alpha-c+e}{3}, \quad w_{r}(e)=\frac{\alpha+2(c-e)}{3}, q(e)=\frac{\alpha-c+e}{6 \beta} .
$$

In the first stage, anticipating the outcome in the second and the third stages, firm $R$ maximizes its objective:

$$
\pi_{R}=\left(w_{r}(e)-(c-e)\right) q(e)-\gamma e^{2}=\frac{(\alpha-c+e)^{2}}{18 \beta}-\gamma e^{2} .
$$

The first-order condition leads to

$$
e^{*}=\frac{\alpha-c}{18 \beta \gamma-1}, \quad w_{l}^{*}=\frac{6 \beta \gamma(\alpha-c)}{18 \beta \gamma-1}, \quad w_{r}^{*}=\frac{(6 \beta \gamma-1) \alpha+12 \beta \gamma c}{18 \beta \gamma-1} .
$$


The equilibrium profits, the consumer surplus, and the social surplus are given as

$$
\begin{aligned}
& \pi_{L}^{*}=\frac{18 \beta \gamma^{2}(\alpha-c)^{2}}{(18 \beta \gamma-1)^{2}}, \pi_{R}^{*}=\frac{\gamma(\alpha-c)^{2}}{18 \beta \gamma-1}, \pi_{T}^{*}=\frac{9 \beta \gamma^{2}(\alpha-c)^{2}}{(18 \beta \gamma-1)^{2}}, \\
& C S^{*}=\frac{9 \beta \gamma^{2}(\alpha-c)^{2}}{2(18 \beta \gamma-1)^{2}}, S W^{*}=\frac{\gamma(99 \beta \gamma-2)(\alpha-c)^{2}}{2(18 \beta \gamma-1)^{2}}
\end{aligned}
$$

The sum of profits $\pi_{R}$ and $\pi_{T}$ is

$$
\pi_{R}^{*}+\pi_{T}^{*}=\frac{(27 \beta \gamma-1) \gamma(\alpha-c)^{2}}{(18 \beta \gamma-1)^{2}} .
$$

Vertical integration We solve the game by backward induction.

In the third stage, the profit of firm $I$ and its first-order condition are

$$
\pi_{I}=\left(\alpha-\beta q-w_{l}-(c-e)\right) q-\gamma e^{2}, \quad \frac{\partial \pi_{I}}{\partial q}=\alpha-2 \beta q-w_{l}-(c-e)=0 .
$$

The first-order conditions lead to

$$
q\left(w_{l}, e\right)=\frac{\alpha-c+e-w_{l}}{2 \beta} .
$$

In the second stage, anticipating the outcome in the third stage, group $L$ maximizes its objective:

$$
\pi_{L}=w_{l} q\left(w_{l}, e\right)=\frac{w_{l}\left(\alpha-c+e-w_{l}\right)}{2 \beta} .
$$

The maximization problems lead to

$$
w_{l}(e)=\frac{\alpha-c+e}{2}, q(e)=\frac{\alpha-c+e}{4 \beta} .
$$

In the first stage, the profit of firm $I$ and its first-order condition are

$$
\begin{aligned}
\pi_{I} & \left.=\left(\alpha-\beta q(e)-w_{l} 8 e\right)-(c-e)\right) q(e)-\gamma e^{2}=\frac{(\alpha-c+e)^{2}}{16 \beta}-\gamma e^{2}, \\
\frac{\partial \pi_{I}}{\partial e} & =\frac{\alpha-c+e}{8 \beta}-2 \gamma e=0 .
\end{aligned}
$$

The first-order conditions lead to

$$
e^{* *}=\frac{\alpha-c}{16 \beta \gamma-1}, w_{l}^{* *}=\frac{8 \beta \gamma(\alpha-c)}{16 \beta \gamma-1} .
$$


The equilibrium profits, the consumer surplus, and the social surplus are given as

$$
\begin{aligned}
& \pi_{L}^{* *}=\frac{32 \beta \gamma^{2}(\alpha-c)^{2}}{(16 \beta \gamma-1)^{2}}, \pi_{I}^{* *}=\frac{\gamma(\alpha-c)^{2}}{16 \beta \gamma-1} \\
& C S^{* *}=\frac{8 \beta \gamma^{2}(\alpha-c)^{2}}{(16 \beta \gamma-1)^{2}}, S W^{* *}=\frac{\gamma(56 \beta \gamma-1)(\alpha-c)^{2}}{(16 \beta \gamma-1)^{2}} .
\end{aligned}
$$

We first compare the several values derived in the previous subsections. Simple calculus lead to the following relations:

$$
w_{l}^{*}<w_{l}^{* *}, e^{*}<e^{* *}, q^{*}<q^{* *}, \pi_{L}^{*}<\pi_{L}^{* *}, S W^{*}<S W^{* *}
$$

The mechanism behind those inequalities is similar to that in the previous section.

Comparison The difference between the profits in the two cases is

$$
\pi_{I}^{* *}-\left(\pi_{R}^{*}+\pi_{T}^{*}\right)=\frac{\gamma(\alpha-c)^{2}}{16 \beta \gamma-1}-\frac{(27 \beta \gamma-1) \gamma(\alpha-c)^{2}}{(18 \beta \gamma-1)^{2}}=\frac{(7-108 \beta \gamma) \beta \gamma^{2}(\alpha-c)^{2}}{(18 \beta \gamma-1)^{2}(16 \beta \gamma-1)}<0 .
$$

This result is summarized in Proposition 2 in the main text. 


\section{References}

Arya, A., Mittendorf, B., and Sappington, D.E.M., 2008, 'The Make-or-Buy Decision in the Presence of a Rival: Strategic Outsourcing to a Common Supplier', Management Science 54, pp. $1747-1758$.

Baldwin, C.Y., and Woodard, C.J., 2007, 'Competition in Modular Clusters', Working Paper, Harvard Business School.

Beelaerts van Blokland, W.W.A., Verhagen, W.J.C., and Santema, S.C., 2008, 'The Effects of Co-Innovation on the Value-Time Curve: A Quantitative Study on Product Level', Journal of Business Market Management 2, pp. 5-24.

Bonanno, G. and Vickers, J., 1988, 'Vertical Separation', Journal of Industrial Economics 36, pp. 257-265.

Casadesus-Masanell, R., Nalebuff, B., and Yoffie, D., 2007, 'Competing Complements', Working Paper, Harvard Business School.

Che, Y.-K. and Sákovics, J., 2008, 'Hold-up Problem', in Durlauf, S.N. and Blume, L.E. (eds.), The New Palgrave Dictionary of Economics, Second Edition, (Macmillan, London).

Chen, Y., 2001, 'On Vertical Mergers and Their Competitive Effects', RAND Journal of Economics 32 , pp. 667-685.

Chen, Y., 2005, 'Vertical Disintegration', Journal of Economics and Management Strategy 14, pp. 209-229.

Choi, J. P. and Yi, S.-S., 2000, 'Vertical Foreclosure with the Choice of Input Specifications', RAND Journal of Economics, 31, pp. 717-743.

Coase, R. 1937, 'The Nature of the Firm', Economica 4, pp. 386-405.

Cournot, A. 1838, 'Researches into the Mathematical Principles of the Theory of Wealth', (Macmillan, New York); English translation, N. Bacon, 1897.

Davidson, C., 1988, 'Multiunit Bargaining in Oligopolistic Industries', Journal of Labor Economics 6, pp. 397-422.

Dowrick, S., 1989, 'Union-Oligopoly Bargaining', Economic Journal 99, pp. 1123-1142.

Economides, N. and Salop, S.C., 1992, 'Competition and Integration Among Complements, and Network Market Structure', Journal of Industrial Economics 40, pp. 105-123.

Gal-Or, E., 1999, 'Vertical Integration or Separation of the Sales Function as Implied by Competitive Forces', International Journal of Industrial Organization 17, pp. 641-662.

Gaudet, G. and Long, N.V., 1996, 'Vertical Integration, Foreclosure, and Profits in the Presence of Double Marginalization', Journal of Economics and Management Strategy 5, pp. 409432 . 
Grossman, S. and Hart, O., 1986, 'The Costs and Benefits of Ownership: A Theory of Lateral and Vertical Integration', Journal of Political Economy 94, pp. 691-719.

Grout, P. 1984, 'Investment and Wages in the Absence of Binding Contracts: A Nash Bargaining Approach', Econometrica 52, pp. 449-460.

Hart, O. and Moore, J., 1990, 'Property Rights and the Nature of the Firm', Journal of Political Economy 98, pp. 1119-1158.

Hart, O. and Tirole, J., 1990, 'Vertical Integration and Market Foreclosure', Brookings Papers on Economic Activity: Microeconomics, pp. 205-276.

Horn, H. and Wolinsky, A., 1988a, 'Bilateral Monopolies and Incentives for Merger', RAND Journal of Economics 19, pp. 408-419.

Horn, H. and Wolinsky, A., 1988b, 'Worker Substitutability and Patterns of Unionization', Economic Journal 98, pp. 484-497.

Klein, B., Crawford, R. and Alchian, A., 1978, 'Vertical Integration, Appropriable Rents, and the Competitive Contracting Process', Journal of Law and Economics 21, pp. 297-326.

Lafontaine, F. and Slade, M., 2007, 'Vertical Integration and Firm Boundaries: The Evidence', Journal of Economic Literature 45, pp. 629-685.

Laussel, D., 2008, 'Buying Back Subcontractors: The Strategic Limits of Backward Integration', Journal of Economics and Management Strategy 17, pp. 895-911.

Lin, P., 2006, 'Strategic Spin-Offs of Input Divisions', European Economic Review 50, pp. 977-993.

Lommerud, K.E., Meland, F., and Sørgard, L., 2003, 'Unionised Oligopoly, Trade Liberalisation and Location Choice', Economic Journal 113, 782-800.

Lommerud, K.E., Meland, F., and Straume, O.R., 2009, 'Can Deunionization Lead to International Outsourcing?', Journal of International Economics 77, 109-119.

Ma, C.-T. A., 1997, 'Option Contracts and Vertical Foreclosure', Journal of Economics and Management Strategy 6, pp. 725-753.

Maruyama, M. and Minamikawa, K., 2009, Vertical Integration, Bundled Discounts and Welfare, Information Economics and Policy 21, pp. 62-71.

Matsushima, N., 2009, 'Vertical Merger and Product Differentiation', Journal of Industrial Economics, 57, pp. 812-834.

Matsushima, N. and Mizuno, T., 2009, 'Vertical Separation as a Defense Against Strong Suppliers', ISER Discussion Paper 0755, Osaka University.

McAfee, R.P. and Schwartz, M., 1994, 'Opportunism in Multilateral Vertical Contracting: Nondiscrimination, Exclusivity, and Uniformity', American Economic Review 84, pp. 21030. 
Mizutani, F. and Uranishi, S., 2011, 'Does Vertical Separation Reduce Cost? An Empirical Analysis of the Rail Industry in OECD Countries,' Discussion Paper Series No.2011-28, Graduate School of Business Administration, Kobe University.

Mumford, K. and Dowrick, S., 1994, 'Wage Bargaining with Endogenous Profits, Overtime Working and Heterogeneous Labor', Review of Economics and Statistics 76, pp. 329-336.

Nalebuff, B.J., 2000, 'Competing Against Bundles', in Peter J. Hammond and Gareth D. Myles, eds., Incentives, Organization, and Public Economics: Papers in Honour of Sir James Mirrlees pp. 323-336, (Oxford University Press, Oxford, UK).

Naylor, R.A., 2002, 'Industry Profits and Competition under Bilateral Oligopoly', Economics Letters 77, pp. 169-175.

O'Brien, D.P. and Shaffer, G., 1992, 'Vertical Control with Bilateral Contracts' RAND Journal of Economics 23, pp. 299-308.

Ordover, J., Saloner, G., and Salop, S., 1990, 'Equilibrium Vertical Foreclosure', American Economic Review, 80, pp. 127-142.

Rey, P. and Tirole, J., 2007, 'A Primer on Foreclosure', in Armstrong, M. and Porter, R.H. (eds.), Handbook of Industrial Organization, Vol. 3 (Elsevier, Amsterdam, The Netherlands).

Riordan, M.H. 1998, 'Anticompetitive Vertical Integration by a Dominant Firm', American Economic Review 88, pp. 1232-1248.

Sonnenschein, H., 1968, 'The Dual of Duopoly Is Complementary Monopoly: or, Two of Cournot's Theories Are One', Journal of Political Economy 76, pp. 316-318.

Tirole, J., 1986, 'Procurement and Renegotiation', Journal of Political Economy 94, pp. 235259.

Williamson, O. 1979, 'Transaction-Cost Economics: the Governance of Contractual Relations', Journal of Law and Economics 22, pp. 233-262.

Williamson, O. 1985, The Economic Institutions of Capitalism: Firms, Markets, Relational Contracting, (The Free Press, New York, USA). 


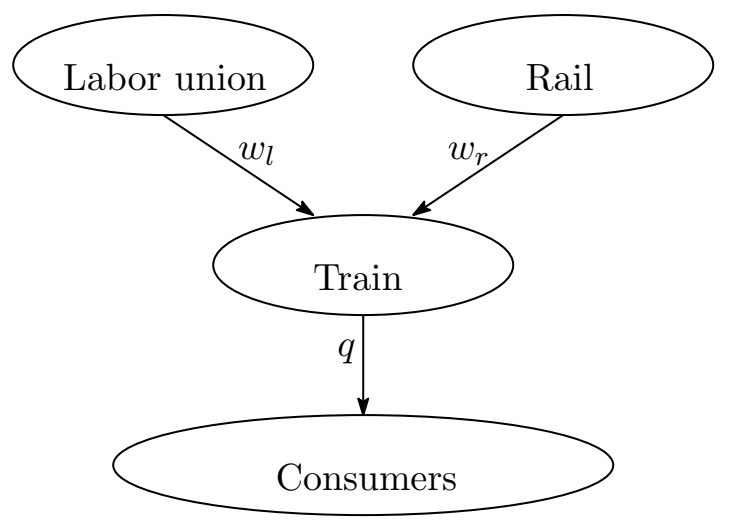

Figure 1: The market structure 


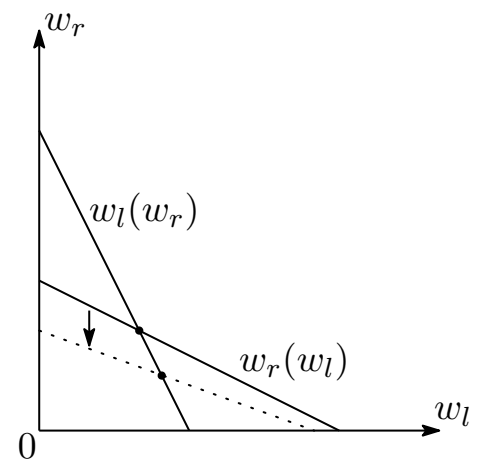

Figure 2: The reaction functions of $L$ and $R$. 